\title{
Ten time-management tips for family physicians
}

Dr. Crosby is a medicolegal consultant and a family, emergency and long-term care physician in Cambridge, Ont. He has lectured nationally and internationally on time-management strategies for physicians. CMAJ asked him to provide some tips on the topic for family physicians.

$\mathrm{F}$ amily physicians often complain that they are "drowning in paperwork," "working longer hours and making less money," "needing more time off" and feeling "tired and pressured" as they run between their responsibilities at home, office, hospital and nursing home. Improved time management can help, but many of us are at a loss as to where to start. Although it is rare for a single time-management strategy to work for everyone, physicians who are willing to dedicate time and money to changing their work habits often end up feeling happier and more satisfied with their work. Here are 10 timemanagement tips that most physicians will find practical and easy to introduce into their daily lives.

\section{Get help}

Meet with your staff about the problem. Set up a mutually convenient, paid, 3-hour-long uninterrupted (redirect phones and pages) Saturday morning meeting. Brainstorm about all the ways that time is wasted in your office, both in their jobs and yours. Come up with strategies that might reduce these inefficiencies. By the end of the meeting set some goals (e.g., to allow more of your daily appointments to be reserved for same-day urgent visits) and set a fixed date (often 3 months is long enough) to attain them. Sometimes, local professional practice management consultants (a lists of such consultants might be available from your provincial medical as$\rightarrow$ sociation) can provide objective help if your team is having a hard time planning changes.

\section{Use a master schedule}

Whether paper or electronic, a master schedule for the entire office can prevent stressful mixups and double-bookings. Ensure that everyone in the office feeds into the master schedule and that it contains all your relevant professional engagements (including normal office hours, emergency department shifts, nursing home visits, house calls, teaching dates, conferences and education events) as well as special occasions (including statutory and staff holidays). Make sure you have at least glanced at your next day's schedule by $5 \mathrm{pm}$ the day before to avoid being surprised by unexpected tasks.

\section{Analyze appointment patterns}

Sit down with your staff and analyze trends in your schedule, such as slow and busy times of the day, week and year. Then coordinate your schedule to reflect these trends. For example, I tend to perform physicals during a more quiet time of the week (Friday) or year (summer). Also, many physicians fail to allow enough time for acute visits during busy periods of the week. In my practice, Mondays tend to be very busy for acute problems, so I book few appointments for that day. However, by later in the week, I often receive fewer acute visits, which allows me to schedule appointments with patients who require more time. Your staff will also be able to help you identify chronic problems with your schedule. For example, you might never allow enough travel time, or you may continually underestimate the time it takes for certain patients or procedures (e.g., seniors or people with dementia). Identify recurring lapses and fix them by booking your schedule accordingly.

\section{Do things in blocks}

All too often family physicians try to be in too many places at once. Maximize your efficiency by booking blocks of time for things such as surgical assisting or minor office procedures. This allows multiple patients to be seen one after the other, and holds you less at the mercy of problems such as operating room delays. Similarly, it's often a waste of time and money to have just 1 or 2 patients in several different nursing homes. Consider focusing on caring for multiple patients in a single nursing home. In your office, consider hiring a nurse to do regular batches of injections (e.g., allergy shots or immunizations - we have "Flu Fridays" in the fall).

\section{Minimize interruptions}

Every day a physician's time is frittered away in hundreds of brief interactions. But several things can be done to minimize this. When you are not seeing patients with appointments, try to avoid talking to anyone except fellow physicians, nurses or out-

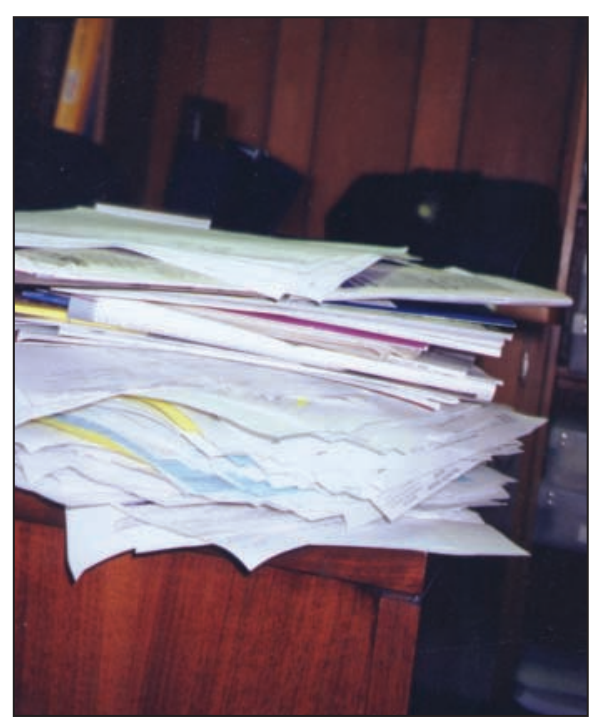

"Papers left in your in-box for too long will seem to mate and have babies." This photo depicts the author's in-box after 2 weeks away from the office. He recommends several strategies, including leaving a buffer day at the end of your holidays to help you deal with paperwork before you are officially back in the office. 
of-town family members of sick patients. Everyone else should book an appointment to talk to you (including patients, family members and pharmaceutical reps). Have a patient handout to explain this and back up your staff by not making exceptions. We all know the feeling of being buttonholed by patients looking to grab you "for just a minute, Doc ...". Have spaces in your schedule available each week for such patients and insist they come back to see you to address their concerns rather than holding you up immediately. Avoiding "voice jail" (or endless phone tag) can also save precious minutes during your day. If it's someone you really want to talk with, leave a message identifying a time when you will definitely be reachable. Minimize telephone interruptions by having your office staff relay faxes back and forth with pharmacies, hospitals, home care agencies and nursing homes. For faxed communications to be effective, however, they must be answered immediately. Have your secretary place them on top of the next patient's chart, so that you can deal with them quickly between patients.

\section{Multi-task}

Have a number of examination rooms running at once. You may be able to pop in to see a patient with a more minor concern while another patient is undressing. Also, have each office equipped to do everything. You won't waste time searching for equipment or running around the office. Try to have your inbox within reach of your desk phone, so that if you do get stuck on hold, you can complete some easy paperwork (e.g., reviewing lab work) as you wait.

\section{Consider dictating}

I dictate all of my charts. It's fast (I talk much faster than I write), cheap (I pay for it by seeing about 3 extra patients a week) and decipherable. With patient consent, I can then send my dictated notes to the emergency department, specialists, lawyers or insurance companies, saving further time at a later date.

\section{Paperwork}

Papers left in your in-box for too long will seem to mate and have babies. Do paperwork daily and touch paper only once, either to file it, shred it, pass it to someone else or direct an appropriate action. If you are asked to complete complicated forms, consider booking an appointment for the patient in question to help you with aspects of the form - you'll be less likely to procrastinate if time is set aside for the form. And make sure that you bill the patient enough for time spent completing paperwork not covered by provincial health insurance. When returning from a holiday, your in-box will often be overflowing. Try booking yourself an extra day to catch up with paperwork before the office is officially open. You'll start your week feeling ahead rather than behind.

\section{Use advice sheets}

Spend some time preparing or collecting advice sheets for common acute and chronic conditions as well as information on support groups, diets, exercise, volunteering and applying for home care. Spoken advice often goes in one ear and out the other, but preprinted materials, with the most appropriate sections circled, give patients reminders to take home. I keep my printed handouts in pigeonholes over my work area, but outside of the exam rooms. Escaping to retrieve an advice sheet, as brief as it is, often helps to terminate an appointment.

\section{Book yourself private time}

Time away from the office is important. When you go home, enjoy life and don't think about your job or take paperwork home with you. Sign out responsibility for patients to large call groups on evenings, weekends and holidays. Subscribe to a caller-ID service and screen your calls. Don't answer the phone if you're off call. Ask yourself, "If I were in the Bahamas, wouldn't they find someone else to fix this?" Physicians who fail to take enough quality time away from the office often end up being less effective in the office.

\section{Final note}

Although inefficiencies can occur in any part of a medical office, it's often the physician who has the most to contribute to fixing the problem. For those who are interested in improving their time-management skills and are willing to spend a little time and money examining their schedule and work habits, there is hope. I hope these 10 tips will help, at least a little.

John W. Crosby

Family Physician

Cambridge, Ont.

Assistant Professor of Medicine

University of Toronto

Toronto, Ont.

\section{Share your tips}

Do you have time-management tips of your own to share? Visit www.cmaj.ca and submit an e-response to this article. After a month, our editors will compile the best tips and share them in an upcoming issue of CMAJ. 